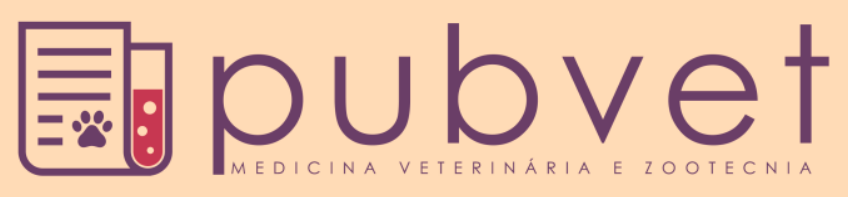

https://doi.org/10.22256/pubvet.v12n3a49.1-5

\title{
Perfil de susceptibilidade antimicrobiana e produção de hemolisina de enterobactérias de psitacídeos em cativeiro
}

\author{
Lenize Cristina Trindade ${ }^{1 *}$, Paulo Tadeu Figueira ${ }^{2}$ \\ ${ }^{I}$ Discente do curso de Farmácia da Pontifícia Universidade Católica do Paraná-PUCPR. Toledo-PR Brasil. E-mail: leniize@ live.com \\ ${ }^{2}$ Professor da Pontifícia Universidade Católica do Paraná, Escola de ciências da vida. Toledo-PR Brasil. E-mail: paulo.figueira@pucpr.br \\ *Autor para correspondência
}

\begin{abstract}
RESUMO. A prática de se obter animais de estimação está cada dia mais inserida na sociedade, esse fato deve-se ao bem-estar e qualidade de vida que o convívio com estes animais traz aos humanos. A procura por animais exóticos, tem se tornado frequente, sendo os psitacídeos um dos grupos mais apreciado para esse fim. Porém, essas aves são passíveis de transmitir patógenos tanto para o homem, quanto para outros animais, representando um relevante fator de risco à saúde pública. Este projeto teve por objetivo realizar a determinação do perfil de susceptibilidade antimicrobiana e da produção de hemolisina em enterobactérias isoladas de psitacídeos em cativeiros do Parque das Aves em Toledo-PR Paraná. Foram analisadas amostras positivas para Escherichia coli (20\% do total de amostras analisadas), previamente identificadas e isoladas e realizados antibiogramas segundo o Método de Kirby \& Bauer. Posteriormente, realizou-se avaliação de fator de virulência, por meio do teste de atividade hemolítica (TAH) semeando as amostras em ágar Sangue, tendo como controle positivo uma amostra de E. coli EHEC e como controle negativo uma amostra de E. coli K12. A interpretação dos valores dos halos obtidos no antibiograma verificou o grau de sensibilidade das amostras de E. coli aos antibióticos, onde notou-se a resistência das amostras a vários antibióticos testados. No teste de TAH identificou-se gama-hemólise. A determinação do perfil de sensibilidade das cepas de E.coli, torna ainda mais relevante a preocupação com a patogenicidade dos microrganismos que essas aves podem portar, tendo em vista o grau de resistência dessas bactérias aos antibióticos testados. Este perfil também possibilitou saber quais antimicrobianos tem ação mais efetiva sobre as bactérias encontradas, possibilitando melhor entendimento sobre a microbiota destes animais.
\end{abstract}

Palavras chave: animais silvestres, Escherichia coli, Salmonella spp.

\section{Antimicrobial susceptibility profile and haemolysin production of enterobacteria from Psittacidae in captivity}

ABSTRACT. The practice of getting pets is increasingly inserted in society; this fact is due to the welfare and quality of life that the living with these animals brings to humans. The search for exotic animals has become frequent, with parrots being one of the groups most appreciated for this purpose. However, these birds are likely to transmit pathogens both to man and to other animals, representing a relevant risk factor for public health. The aim of this work was to determine the profile of antimicrobial susceptibility and hemolysin production in enterobacteria isolated from psittacines of captive of bird park in Toledo city Brazil. Escherichia coli positive samples (20\% of the analysed sample), previously identified and isolated, were analyzed and performed according to Kirby \& Bauer method. Subsequently, virulence factor evaluation was performed by hemolytic activity test (TAH) by sowing the samples in Blood agar, having as a positive control sample of $E$. coli EHEC 
and as negative controls a sample of $E$. coli $\mathrm{K} 12$. The interpretation of the values of halos obtained in the antibiogram verified the degree of sensitivity of E. coli samples to antibiotics, where the resistance of the samples to several antibiotics tested was noted. Gamma haemolysis was identified in the TAH test. The determination of the sensitivity profile of strains of $E$. coli makes even more relevant the concern with microorganism's pathogenicity that these birds can carry, considering the degree of resistance of these bacteria to the tested antibiotics. This profile also made it possible to know which antimicrobials have a more effective action on the bacteria found, allowing a better understanding of the microbiota of these animals.

Keywords: Escherichia coli, Salmonella spp., wild animals

\section{Perfil de susceptibilidad antimicrobiana y producción de hemolisina de enterobacterias de psitácidos en cautiverio}

RESUMEN. La práctica de obtener animales domésticos está cada día más insertada en la sociedad, ese hecho se debe al bienestar y calidad de vida que la convivencia con estos animales trae a los humanos. La búsqueda de animales exóticos, se ha vuelto frecuente, siendo los psitácidos uno de los grupos más apreciado para ese fin. Sin embargo, estas aves son pasibles de transmitir patógenos tanto para el hombre, como para otros animales, representando un relevante factor de riesgo a la salud pública. Este proyecto tuvo como objetivo realizar la determinación del perfil de susceptibilidad antimicrobiana y de la producción de hemolisina en enterobacterias aisladas de psitácidos de cautiverios del parque de las aves en la ciudad de Toledo (Brasil). Se analizaron muestras positivas para Escherichia coli (20\% del total de muestras analizadas), previamente identificadas y aisladas y realizados antibiogramas según el Método de Kirby \& Bauer. Se realizó evaluación de factor de virulencia, por medio de la prueba de actividad hemolítica (PAH) sembrando las muestras en agar Sangre, teniendo como control positivo una muestra de $E$. coli EHEC y como control negativo una muestra de E. coli K12. La interpretación de los valores de los halos obtenidos en el antibiograma verificó el grado de sensibilidad de las muestras de E. coli a los antibióticos, donde se observó la resistencia de las muestras a varios antibióticos probados. En la prueba de PAH se identificó gamma-hemólisis. La determinación del perfil de sensibilidad de las cepas de E.coli, torna aún más relevante la preocupación por la patogenicidad de los microorganismos que estas aves pueden portar, teniendo en cuenta el grado de resistencia de estas bacterias a los antibióticos probados. Este perfil también posibilitó saber qué antimicrobianos tiene acción más efectiva sobre las bacterias encontradas, posibilitando mejor entendimiento sobre la microbiota de estos animales.

Palabras clave: animales silvestres, Escherichia coli, Salmonella spp

\section{Introdução}

Os animais de estimação vêm exercendo um papel cada vez mais importante no arranjo familiar segundo Faraco \& Seminotti (2004), tal prática é cada vez mais justificada por estudos que comprovam os benefícios deste convívio ao bemestar e qualidade de vida humana (Giumelli \& Santos, 2016). O crescente interesse por animais de estimação torna ainda mais frequente a escolha por animais silvestres. Entre os animais preferidos estão as aves, no intuito de se obter interação e companheirismo os psitacídeos são o grupo mais apreciado para esse fim, por serem animais vocais, inteligentes e com habilidades de imitar sons humanos (Sick, 1997, Allgayer \& Cziulik, 2007). Além dos benefícios que este convívio oferece, por se tratar de animais silvestres, representam um relevante fator de risco à saúde pública por poderem albergar microrganismos patogênicos passíveis de serem transmitidos a humanos e outros animais domésticos (Hemsworth \& Pizer, 2006, Raso, 2007).

Os psitacídeos possuem microbiota natural composta exclusivamente por bactérias Grampositivas, portanto, a presença de enterobactérias é considerada desequilíbrio da microbiota e 
indicativo de infecção (Hoefer, 1997, Cubas et al., 2014). E.coli e Salmonella spp. são enterobactérias de elevado potencial patogênico e estão entre os principais microrganismos que acometem aves (Corrêa et al., 2013).

A escassez de estudos sobre estes
microrganismos e principalmente a
suscetibilidade dos mesmos, frente aos
antimicrobianos disponíveis para tratamento,
comprova a necessidade de se produzir
informações científicas e assim colaborar no
tratamento medicamentoso destes animais, evitar
a perda dos mesmos e minimizar os riscos à saúde
pública (Lopes et al., 2016).

Este trabalho teve como objetivo realizar a determinação do perfil de susceptibilidade antimicrobiana e produção de hemolisina em Escherichia coli. e Salmonella spp. isoladas de amostras coletadas de aves cativas do viveiro do Parque das Aves em Toledo-PR.

\section{Material e Métodos}

A pesquisa foi iniciada após a aprovação do Comitê de Ética no Uso de Animais da Pontifícia Universidade Católica do Paraná (CEUAPUCPR). O estudo foi realizado em amostras coletadas via de $s w a b$ cloacal e de cavidade oral mediante contenção física de aves do viveiro do Parque das Aves em Toledo-PR.

Foram coletadas amostras de 10 papagaios verdadeiros (Amazona aestiva), 1 periquito maracanã (Ara chloroptera) e de 1 arara Canindé (Ara ararauna), totalizando 12 pássaros e 24 amostras. Foram analisadas apenas as amostras positivas para Escherichia coli, previamente identificadas e isoladas. Não se obteve amostras positivas para Salmonella spp.. As cepas de E. coli encontradas foram cultivadas em Caldo BHI (brain heart infusion) e incubadas a $37^{\circ} \mathrm{C}$ por 24 horas.

Com as amostras obtidas após a incubação foram realizados os antibiogramas segundo o Método de Kirby-Bauer. Alíquotas de $0,1 \mathrm{~mL}$ de caldo foram dispostas de maneira uniforme em placas contendo Ágar Müeller-Hinton, acrescentando em seguida, os discos contendo antibióticos. As cepas de E. coli foram desafiadas aos seguintes antibióticos: cefaclor $(30 \mu \mathrm{g})$, ceftriaxona $(30 \mu \mathrm{g}), \quad$ ciprofloxacino $(5 \mu \mathrm{g})$, enrofloxacina $(5 \mu \mathrm{g})$, estreptomicina $(10 \mu \mathrm{g})$, gentamicina $(10 \mu \mathrm{g})$, levofloxacino $(5 \mu \mathrm{g})$, norfloxacino $(10 \mu)$, tetraciclina $(30 \mu \mathrm{g})$ e tobramicina $(10 \mu \mathrm{g})$. Por fim, as placas foram incubadas a $37^{\circ} \mathrm{C}$ por 24 horas, sendo realizada a leitura dos halos obtidos após este período.

A avaliação de fator de virulência foi obtida pelo teste de atividade hemolítica (TAH). As amostras foram semeadas em ágar Sangue (5\% de sangue ovino desfibrinado) e incubadas a $37^{\circ} \mathrm{C}$ por 24 horas. Uma amostra de E. coli EHEC (E.coli enterohemorrágica) foi utilizada como controle positivo e para o controle negativo uma amostra de E. coli K12.

\section{Resultados e Discussão}

Não se obteve nenhum resultado positivo para Salmonella spp. A ausência de isolamento desta bactéria mostra-se de acordo com estudos realizados por Corrêa et al. (2013) que analisaram amostras de 15 aves, entre elas papagaios e uma arara e como no presente estudo, não obtiveram isolamento da bactéria. Assim, como no resultado deste estudo, a ausência de Salmonella spp. era esperada, pois as aves utilizadas para este estudo encontravam-se saudáveis. Das 24 amostras analisadas, 5 se mostraram positivas para E. coli, denominadas de 1 a 5 , referentes a $20 \%$ do total de amostras coletadas, sendo 3 delas provenientes de swab cloacal e 2 de swab de bico. Resultado condizente com os encontrados por MariettoGonçalves et al. (2010), que analisaram 89 amostras de swab cloacal de três espécies diferentes de psitacídeos, detectando a presença de E. coli $\mathrm{em} 19 \%$ das amostras analisadas. A taxa de contaminação por E. coli elevada pode estar relacionada as condições em que se encontram esses animais, por encontrarem-se em cativeiro, ambiente que facilita a dispersão de patógenos. Ao analisar amostras cloacais de 50 aves criadas em criatório conservacionista Mattes et al. (2005) constataram a presença de E. coli em $20 \%$ das aves, dentre as quais oito eram papagaios da espécie A. aestiva.

A alta taxa de contaminação é um dado preocupante, visto que estas cepas são potencialmente patogênicas, Knöbl et al. (2011) investigaram os serogrupos e propriedades de virulência de $E$. coli isoladas de 24 aves psittacinas doentes, verificando que dois isolados apresentavam patótipos enteropatogênicos de $E$. coli (EPEC).

Para a determinação do perfil de suscetibilidade foram interpretados os resultados dos ensaios do antibiograma. Foi possível verificar o crescimento dos microrganismos e a formação de halos de inibição satisfatórios, com o 
auxílio de um paquímetro, realizou-se a medição manual das zonas de inibição circundantes aos discos, obtendo-se os valores de halo em $\mathrm{mm}$ de cada antimicrobiano.

Os valores obtidos foram analisados segundo a metodologia e classificados como sensível, intermediário ou resistente, determinando o grau de sensibilidade das amostras de E. coli aos antibióticos testados (Figura 1). As amostras 1 e 5 apresentaram alto grau de resistência sendo a amostra 1 resistente a $90 \%$ e a amostra 5 a $100 \%$ dos antimicrobianos testados. A amostra 3 foi resistente a 50\%. As amostras 3 e 4 mostraram-se sensíveis, respectivamente a $70 \%$ e $80 \%$ dos antimicrobianos, revelando graus variáveis de resistência das amostras aos vários antibióticos testados, assim como no estudo de Machado et al. (2016).

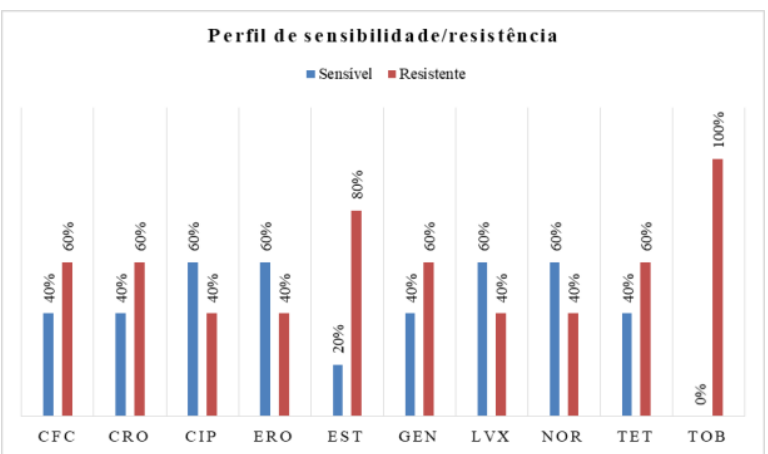

Figura 1. Perfil de sensibilidade/resistência a antibióticos das amostras de Escherichia coli isoladas de psitacídeos cativos CFC: Cefaclor; CRO: Ceftriaxona; CIP: ciprofloxacino; ENR: Enrofloxacino; EST: Estreptomicina; GEN: Gentamicina; LVX: Levofloxacino; Norfofloxacino: NOR; TET: Tetraciclina e TOB: Tobramicina

Os antibióticos da classe das quinolonas (Ciprofloxacino, Enrofloxacino, Levofloxacino e Norfofloxacino) apresentaram ação mais eficaz e entre eles o enrofloxacino e o ciprofloxacino produziram maior inibição do crescimento das cepas, enquanto os aminoglicosídeios (Estreptomicina, Gentamicina e Tobramicina) apresentaram baixa eficácia, observou-se maior resistência das cepas aos antimicrobianos desta classe, no caso da tobramicina, todas as amostras apresentaram resistência.

No teste de atividade hemolítica, as amostras de $E$. coli apresentaram um padrão de $\gamma$-hemólise, indicando ação não hemolítica sobre as hemácias presentes no ágar, resultado discrepante do encontrado por Marietto-Gonçalves et al. (2010) que obteve 5 cepas com capacidade de causar hemólise.
$O$ perfil de sensibilidade das amostras encontradas no presente trabalho, assim como em outros estudos realizados com psitacídeos torna ainda mais relevante os riscos à saúde pública que os patógenos que podem estar presentes nestas aves podem oferecer (Evans et al., 2014), apesar de não apresentarem ação hemolítica no TAH, as bactérias apresentaram alto grau de resistência aos antibióticos testados, evidenciando o surgimento de bactérias resistentes aos antimicrobianos utilizados no tratamento de infecções, preocupação também apontada por Hidasi et al. (2013) em seu trabalho.

\section{Conclusões}

A determinação do perfil de sensibilidade das cepas de E. coli tornou ainda mais relevante a preocupação com a patogenicidade dos microrganismos que essas aves podem portar, tendo em vista o grau de resistência dessas bactérias aos antibióticos testados. Este perfil também possibilitou saber quais antimicrobianos tem ação mais efetiva sobre as bactérias encontradas, possibilitando melhor entendimento sobre a microbiota destes animais. Fica evidente a necessidade de mais estudos a respeito, bem como a tomada dos devidos cuidados com estes animais, a fim de se evitar as perdas dos mesmos e minimizar os riscos à saúde pública.

\section{Referências bibliográficas}

Allgayer, M. C. \& Cziulik, M. 2007. Reprodução de psitacídeos em cativeiro. Revista Brasileira de Reprodução Animal, 31, 344-350.

Corrêa, I. M. O., Flores, F., Schneiders, G. H., Pereira, L. Q., Brito, B. G. \& Lovato, M. 2013. Detecção de fatores de virulência de Escherichia coli e análise de Salmonella spp. em psitacídeos. Pesquisa Veterinária Brasileira, 33, 241-246.

Cubas, Z. S., Silva, J. C. R. \& Dias, J. L. C. 2014. Tratado de animais selvagens-medicina veterinária. Editora Roca.

Evans, E. E., Mitchell, M. A., Whittington, J. K., Roy, A. \& Tully Jr, T. N. 2014. Measuring the level of agreement between cloacal gram's stains and bacterial cultures in Hispaniolan Amazon parrots (Amazona ventralis). Journal of Avian Medicine and Surgery, 28, 290-296.

Faraco, C. B. \& Seminotti, M. 2004. A relação homem-animal e a prática veterinária. Revista Conselho Federal de Medicina Veterinária, 10,57-62. 
Giumelli, R. D. \& Santos, M. C. P. 2016. Convivência com animais de estimação: um estudo fenomenológico. Revista da Abordagem Gestáltica: Phenomenological Studies, 22, 49-58.

Hemsworth, S. \& Pizer, B. 2006. Pet ownership in immunocompromised children - a review of the literature and survey of existing guidelines. European Journal of Oncology Nursing, 10, 117-127.

Hidasi, H. W., Neto, J. H., Moraes, D. M. C., Linhares, G. F. C., Sá Jayme, V. \& Andrade, M. A. 2013. Enterobacterial detection and Escherichia coli antimicrobial resistance in parrots seized from the illegal wildlife trade. Journal of Zoo and Wildlife Medicine, 44, 1-7.

Hoefer, H. L. 1997. Doenças do trato gastrointestinal. In: R.B., A., Clubb, S. L., Dorestein, G. M. \& Quesenbery, K. (eds.) Medicina aviária e cirurgia. Saunders Company, Philadelphia.

Knöbl, T., Saidenberg, A., Moreno, A. M., Gomes, T. A. T., Vieira, M. A. M., Leite, D. S., Blanco, J. E. \& Ferreira, A. J. P. 2011. Serogroups and virulence genes of Escherichia coli isolated from psittacine birds. Pesquisa Veterinária Brasileira, 31, 916-921.

Lopes, E. S., Maciel, W. C., Castro, R. S. T., Albuquerque, Á. H., Vasconcelos, R. H., Machado, D. N., Bezerra, W. G. A. \& Santos, I. C. L. 2016. Isolamento de Salmonella spp. e Escherichia coli de psittaciformes: relevância em saúde pública. Arquivos do Instituto Biológico, 83, 1-10.
Machado, D. N., Lopes, E. S., Albuquerque, Á. H., Bezerra, W. G. A., Horn, R. V., Lima, S. V. G., Siqueira, R. A. S., Beleza, A. J. F., Oliveira, F. R. \& Cardoso, W. M. 2016. Detection and evaluation of the antimicrobial sensibility profile of enterobacteria isolated from captive Grey-breasted parakeet (Pyrrhura griseipectus). Arquivo Brasileiro de Medicina Veterinária e Zootecnia, 68, 1732-1736.

Marietto-Gonçalves, G. A., Almeida, S.M., Lima, E.T., Andreatti-Filho, R.L. 2010. Detecção de Escherichia coli e Salmonella spp. em microbiota intestinal de Psittaciformes em fase de reabilitação para soltura. Brazilian Journal Research of Animal Science, 47, 185-189.

Mattes, B. R., Consiglio, S. A. S., Almeida, B. Z., Guido, M. C., Orsi, R. B., Silva, R., Costa, A., Ferreira, A. J. P. \& Knöbl, T. 2005. Influência da biossegurança na colonização intestinal por Escherichia coli em psitacídeos. Arquivos do Instituto Biológico, 72, 13-16.

Raso, T. F. 2007. Tratado de animais selvagens. Roca, São Paulo, Brasil.

Sick, H. 1997. Ordem psitaciformes. In: Ornitologia Brasileira, Rio de Janeiro: Nova Fronteira, p. 351-82. Nova Fronteira, Rio de Janeiro, Brasil.

\footnotetext{
Article History:

Received 6 November 2017

Accepted 12 December 2017

Available online 10 February 2018

License information: This is an open-access article distributed under the terms of the Creative Commons Attribution License 4.0, which permits unrestricted use, distribution, and reproduction in any medium, provided the original work is properly cited.
} 